\title{
Does the presence of anhydramnios affect the duration of medical abortion?
}

\author{
Oya Soylu Karapinar, Arif Güngören, Kenan Dolapçioğlu, Dilek Benk Şilfeler, \\ Raziye Keskin Kurt, Hanifi Şahin, Ali Ulvi Hakverdi \\ Department of Obstetrics and Gynecology, Mustafa Kemal University Faculty of Medicine, Hatay, Turkey
}

\begin{abstract}
Objectives: The aim of the study was to determine whether anhydramnios affected the duration of medical abortion in cases with various indications as compared to cases with normal amniotic fluid volume.

Material and methods: Patients who were admitted to our clinic because of medical abortion between January 2010-December 2013 were included in this retrospective study. A total of 32 pregnant women with anhydramnios (study group) and 67 pregnant women with normal amniotic fluid volume but with fetal abnormality (control group) were included in the study. Patient age, gravidity, parity, gestational age, previous delivery route, and duration of the abortion were recorded.

Results: Mean duration of the abortion in the study group was $71.93 \pm 47.51 \mathrm{~h}$ as compared to $79.08 \pm 52.62 \mathrm{~h}$ in the control group. There were no statistically significant differences between the two groups in terms of duration of the abortion $(p=0.516)$. Also, we found no statistically significant differences in duration of the abortion with regard to previous delivery route $(p=0.220)$.

Conclusions: There were no statistically significant differences between the study group and controls in terms of duration of the abortion. In addition, neither parity nor previous delivery route affected the duration of the abortion.
\end{abstract}

Key words: medical abortion, anhydramnios, duration of abortus

Ginekologia Polska 2016; 87, 9: 635-638

\section{INTRODUCTION}

Termination of pregnancy (TOP) remains one of the most common procedures in obstetrics and gynecology, with the estimated 50 million induced abortions each year worldwide [1]. Furthermore, due to the introduction of successful large-scale antenatal screening programs for the detection of chromosomal abnormalities and major structural fetal malformations, first and second-trimester abortions are also on the rise $[2,3]$.

There are cases which require medical abortion due to severe structural malformations, genetic disorders, and intrauterine fetal demise. In these cases, prostaglandin (misoprostol) is administered. The use of misoprostol, a synthetic 15-deoxy-16-hydroxy-16-methyl analog of the naturally occurring prostaglandin E1, for termination of pregnancy (TOP) was first described in 1994 [4]. Since then, this agent has been widely used for pregnancy termination due to its low cost, effectiveness, and drug stability at ambient temperature [5], as well as the fact that it can be readily used in several ways, such as sublingual, rectal, vaginal and oral routes. Also, history of cesarean section does not contraindicate the use of misoprostol [6], but caution and lower dose of misoprostol is required due to elevated risk of uterine rupture, regardless of gestational age [7]. The mode of administration, type, and dosage of misoprostol can lead to differences in induction to abortion time interval [8]. Furthermore, factors such as previous cesarean section, increasing gestational age, nulliparity, and amniotic fluid volume can influence the duration of a medical abortion [9]. In this retrospective study, we aimed to determine whether anhydramnios affected the duration of the abortion in case of medical abortion with various indications, and compare it with cases with normal amniotic fluid, as well as to investigate whether previous history of cesarean section impacted the delay of the abortion.

\section{MATERIAL AND METHODS}

This retrospective study was conducted at the Department of Obstetrics and Gynecology, Mustafa Kemal Univer- 
sity Hospital in Hatay, Turkey. Patients who were admitted to our clinic and deemed eligible for medical abortion between January 2010-December 2013 were included in the study. The study group consisted of 32 pregnant women with anhydramnios and the control group included 67 pregnant women who had normal amniotic fluid volume with various anomalies. The abortus indications for the abortion of the control group were as follows: spina bifida, hydrocephalus, encephalocele, anencephaly, hydrops fetalis, multiple anomalies, heart anomalies (hypoplastic left heart), down syndrome, Beta thalassemia, sickle cell anemia and cystic hygroma, and fetal demise. Age, gravidity, parity, gestational age, obstetric history, indications for abortion, duration of abortus of the patients were recorded. Multiple pregnancies were excluded from the study. Local Ethics Committee approved of the study. All participants gave their written informed consent for the study and pregnancy termination.

The method used for termination of pregnancy was chosen with respect to the history of previous cesarean section. Misoprostol was used for medical abortion as: $200 \mu \mathrm{g}$ p.o. and $200 \mu \mathrm{g}$ vaginally twice a day in patients who had a history of cesarean section, and $200 \mu \mathrm{g}$ p.o. and $200 \mu \mathrm{g}$ vaginally thrice a day in patients who had a history of vaginal birth and nulliparity. We used a lower dose misoprostol in patients who had previous cesarean section due to the risk of uterine rupture. After medical abortion, routine revision curettage was not performed. Spontaneous expulsion of the placenta was awaited for up to $60 \mathrm{~min}$. Digital examination and curettage were reserved for cases in which expulsion did not occur or was incomplete on the basis of clinical and/or sonographic findings.

\section{Statistical analysis}

Values shown in the text and the tables are mean \pm SD. Statistical analysis was performed using the SPSS (Statistical Package for the Social Sciences) 21.0 Evaluation for Windows. Student T test was used for the analysis between the anhydramnios and the control groups to measure baseline characteristics such as age, parity, gestational age, and duration of abortion. Correlations between the cesarean section, vaginal birth and nulliparity were assessed by one-way and ANOVA tests. The $p$-value of $<0.05$ was considered as statistically significant.

\section{RESULTS}

Between 2010-2013, 99 women underwent a medical termination for a prenatally recognized anhydramnios and fetal abnormality, with normal amniotic fluid volume, between 10 and 27 weeks of gestation in our clinic. Out of these, 32 (32.3\%) patients had anhydramnios (study group) and 67 (67.7\%) had some anomalies with normal amniotic fluid (control group). Mean patient age was $28.10 \pm 5.72$ (15-41) and mean gestational age was $17.94 \pm 3.40$ (10-27) weeks. Sixty-one (61.6\%) patients had previous vaginal delivery, 28 (28.3\%) had previous cesarean section, and $10(10.1 \%)$ patients were nulliparous. Mean gravidity was 2.68 ( \pm 1.33) (minimum 1-maximum 6) and 2.43 ( \pm 0.85) (minimum 1-maximum 5) in the anhydramnios group and in the control group, respectively. There were 5 (15.6\%) primigravidas in the anhydramnios group and 5 primigravidas (7.5\%) in the control group. Demographic data of the study and control group patients are presented in Table 1.

Mean duration of the abortion was $71.93 \pm 47.51 \mathrm{~h}$ and $79.08 \pm 52.62 \mathrm{~h}$ in in the anhydramnios group and the control group, respectively. There were no statistically significant differences between the two groups in terms of duration of the abortion $(p=0.516)$. If we compare both groups with regard to the necessity of post-abortion curettage, 21 patients $(65.6 \%)$ in anhydramnios group and 57 patients $(85.1 \%)$ in the control group required revision curettage. There was a statistically significant difference between both groups as far as the need for revision curettage is concerned $(p=0.028)$. The anhydramnios group required revision curettage less often than the control group.

Mean duration of the abortion was $69.95 \pm 31.24 \mathrm{~h}$ in patients with a history of vaginal birth, and $87.07 \pm 74.38 \mathrm{~h}$ in patients with a history of cesarean section. Primigravidas had mean duration of the abortion of $91.77 \pm 68.06 \mathrm{~h}$. There were no statistically significant differences in duration of the abortion with regard to obstetric history $(p=0.220)$.

Table 1. Demographic data and duration of the abortion in the study group and controls

\begin{tabular}{|l|c|c|c|}
\hline & $\begin{array}{c}\text { Study group } \\
\text { (anhydramnios) } \\
\mathbf{n = 3 2}\end{array}$ & $\begin{array}{c}\text { Control group } \\
\text { (normal amniotic fluid volume) } \\
\mathbf{n}=67\end{array}$ & $\mathbf{p}$ \\
\hline Maternal age & $29.0( \pm 6.52)$ & $27.6( \pm 5.29)$ & 0.282 \\
\hline Gravidity & $2.68( \pm 1.33)$ & $2.43( \pm 0.85)$ & 0.254 \\
\hline Parity & $2.31( \pm 1.65)$ & $2.14( \pm 1.15)$ & 0.893 \\
\hline Gestational age at termination (week) & $19.7( \pm 2.9)$ & $17.08( \pm 3.29)$ & 0.0001 \\
\hline Duration of abortion (hour) & $71.93( \pm 47.51)$ & $79.08( \pm 52.62)$ & 0.516
\end{tabular}




\section{DISCUSSION}

Prenatal screening is a fundamental component of modern obstetric practice and has enabled millions of women to progress through a pregnancy with confidence with regard to the structural integrity of their fetus. On occasion, however, a significant fetal abnormality will be diagnosed and some women will elect to interrupt the pregnancy following counseling about the potential outcomes of such a decision [10]. TOP in the second trimester constitutes about $10-15 \%$ of all pregnancies and most TOPs due to fetal abnormalities occur after the first trimester of pregnancy. Various mechanical and pharmacological techniques have been attempted, including laminaria, Foley balloon traction, and prostaglandin analogs. Prostaglandins are the mainstay of medical terminations over 13 weeks of gestation, either as a single drug or combined with mifepristone [10, 11]. Misoprostol has been applied in different doses and routes for the second trimester TOP [12]. Various doses have been used, ranging from 200 to $800 \mu \mathrm{g}$ at intervals ranging from 3 to $12 \mathrm{~h}$ [13-15]. Doses of 600 and $800 \mu \mathrm{g}$ had comparable effects on the abortion rates, but are associated with higher incidence of fever, diarrhea, nausea, and vomiting [16]. Vaginal administration of misoprostol is more effective than other routes of administration and the incidence of side effects is lower [17-18].

Although many studies on the effectiveness and possible complications of misoprostol use for pregnancy termination in a normal uterus have been published, few have addressed the specific subject of the scarred uterus due to cesarean section using misoprostol as the single abortifacient agent [19-21]. History of cesarean section does not contraindicate the use of misoprostol [6], but caution and lower dose of misoprostol are required due to the higher risk of uterine rupture, regardless of gestational age [7]. There are little data available regarding the optimal dosage of misoprostol in second-trimester pregnancy terminations in women with previous caesarian sections [22]. Therefore, misoprostol was used for medical abortion as: $200 \mu \mathrm{g}$ p.o. and $200 \mu \mathrm{g}$ vaginally twice a day in patients with a history of cesarean section, and $200 \mu \mathrm{g}$ p.o. and $200 \mu \mathrm{g}$ vaginally thrice a day in patients with a history of vaginal birth and nulliparity. Notably, mean dose of misoprostol necessary to induce an abortion was lower in the cesarean group as compared to the vaginal birth group and nulliparous patients. As reported in other studies [23,24], we observed no statistical differences between the cesarean and the vaginal birth groups in the delay between induction and abortion, and in particular in the duration of the abortion. The lower dose of misoprostol used in the group of women with a history of cesarean section did not impact the delay to abortion significantly. This is important since prolonged induction of labor up to $24 \mathrm{~h}$ has been correlated with a higher risk of uterine rupture [25]. Furthermore, we found no statistical differences between nulliparous patients and cesarean and vaginal birth (multiparous women) groups in the duration of abortion. Median duration of the abortion was reduced by $25 \%$ in multiparous women as compared to nulliparous women, which may be attributed to the faster ripening of the cervix after a previous spontaneous delivery [26]. A correlation between obstetric history was also observed by Jannet et al. In their study, which consisted of 106 terminations of pregnancy with a combination of $600 \mathrm{mg}$ mifepristone and $400 \mu \mathrm{g}$ misoprostol, the time interval between the first induction and fetal expulsion was significantly shorter in multiparous than in primiparous women [27]. In a study by Wagner, the time interval was prolonged in case of previous cesarean section and nulliparity as compared to previous spontaneous delivery [9]. In contrast, in our study parity and previous delivery route did not seem to affect the duration of the abortion.

Factors determining the duration of second trimester pregnancy termination were evaluated by various authors, but the effect of anhydramnios has not yet been clarified. For example, there were three main factors which influenced the duration of the abortion in a study by Dickinson and Doherty. Increasing gestational age, nulliparity, and advanced maternal age were associated with prolongation of the abortion [28]. In the study by Wagner, the parameters with significant influence were gestational age at the time of induction, obstetric history, and nulliparity. Similarly to these two studies, Norbert et al., observed a prolonged induction time with increasing gestational age and attributed this to the need for greater cervical dilatation due to the increasing fetal size. It could therefore be argued that the prolonged induction interval with gestational age could be due a reduction of the receptivity of the uterus to prostaglandins [9]. Multiparous women responded to the vaginal misoprostol with a shorter induction-delivery interval than nulliparous women, a phenomenon also observed by prior studies using pretreatment with mifepristone $[26,29]$. This can be attributed to the faster ripening of the cervix after a previous spontaneous delivery. A longer time interval in women with a previous caesarean section in the study of Wagner could be due to the absence of a previous spontaneous delivery [9]. In the study by Dickinson, higher maternal age was associated with an increased requirement for surgical intervention, which is consistent with the reports of Ashok et al. [28]. Sak et al., studied the factors influencing the duration of misoprostol-induced abortion in the second trimester and found the induction-to-abortion interval to be longer in patients with hyperglycemia and advanced gestational age [30].

Only in one study, patients who received prostaglandins for termination classified according to the amniotic fluid 
volume (normal, polyhydramnios, and oligohydramnios). In that study, no significant differences were found about the median time interval between the first induction and expulsion in the three groups [9]. In our study, anhydramnios did not affect the duration of the abortion as compared to patients with normal amniotic fluid volume. To the best of our knowledge, this study has been the first to evaluate the effect of anhydramnios in the second trimester pregnancy termination.

\section{CONCLUSIONS}

The presence of anhydramnios in the second trimester termination does not affect the duration of the abortion. In addition, neither parity nor previous delivery route influence the duration of the abortion.

\section{ACKNOWLEDGEMENTS}

The authors wish to thank the participants of the study for their invaluable effort and time, as well as the Health and University Management for permission to carry out the study.

\section{Conflict of interest}

The authors declare that there are no conflicts of interest.

\section{REFERENCES}

1. Segal ST, LaGuardia KD. Termination of pregnancy - a global view. Bailliere's Clin Obstet Gynaecol. 1990; 4: 235-247.

2. Liu S, Joseph KS, Kramer MS, [et al.]. Relationship of prenatal diagnosis and pregnancy termination to overall infant mortality in Canada. JAMA. 2002, 287, 1561-1567.

3. Lalitkumar S, Bygdeman M, Gemzell-Danielsson K. Mid-trimester induced abortion: a review. Hum Reprod Update. 2007, 13, 37-52.

4. Jain JK, Mishell Jr DR. A comparison of intravaginal misoprostol with prostaglandin E2 for termination of second-trimester pregnancy. NEngl J Med. 1994, 331, 290-293.

5. Pongsatha S, Tongsong T. Misoprostol for second trimester termination of pregnancies with prior low transverse cesarean section. Int J Gynaecol Obstet. 2003, 80, 61-62.

6. Choy-Hee L, Raynor BD. Misoprostol induction of labor among women with a history of cesarean delivery. Am J Obstet Gynecol. 2001, 184, 1115-1117.

7. Berghahn L, Christensen D, Droste S. Uterine rupture during second trimester abortion associated with misoprostol. Obstet Gynecol. 2201, 98, 976-977.

8. De Heus R, Graziosi GC, Christiaens GC, [et al.]. Medical management for termination of second and third trimester pregnancies: a comparison of strategies. Eur J Obstet Gynecol Reprod Biol. 2004, 116, 16-21.

9. Norbert W, Harald A, Markus H, [et al.]. Factors influencing the duration of late first and second-trimester termination of pregnancy with pro- staglandin derivates. Eur J of Obstetrics Gynecology and Reproductive Biology. 2011, 155, 75-78.

10. Lalitkumar S, Bygdeman M, Gemzell-Danielsson K. Mid-trimester induced abortion: a review. Hum Reprod Update. 2007, 13, 37-52.

11. Talat Umut KD, Arzu D, Ilay G [et al.]. Effect of cervical length on second trimester pregnancy termination. J Obstet Gynaecol Res. 2011, 6, 505-510.

12. Bebbington MW, Kent N, Lim K, [et al.]. A randomized controlled trial comparing two protocols for the use of misoprostol in mid-trimester pregnancy termination. Am J Obstet Gynecol. 2002, 187, 853-857.

13. Dickinson JE, Godfrey M, Evans SF. Efficacy of intravaginal misoprostol in second-trimester pregnancy termination: A randomized controlled trial. J Maternal Fetal Medicine. 1998, 7, 115-119.

14. Dickinson JE, Evans SF. The optimization of intravaginal misoprostol dosing schedules in second-trimester pregnancy termination. Am J Obstet Gynecol. 2002, 186, 470-474.

15. Jain JK, Kou J, Mishell R. A comparison of two dosing regimens of intravaginal misoprostol for second trimester pregnancy termination. Obstet Gynecol. 1999, 93, 571-575.

16. Herabutya Y, Chanrachakul B, Punyavachira P. Vaginal misoprostol in termination of second trimester pregnancy. J Obstet Gynaecol Res. 2000, $26,121-125$.

17. Nigam A, Singh VK, Prakash A. Vaginal vs. oral misoprostol for mid-trimester abortion. Int J Gynecol Obstet. 2006, 92, 270-271.

18. Ho PC, Blumenthal PD, Gemzell-Danielsson K, [et al.]. Misoprostol for the termination of pregnancy with a live fetus at 13 to 26 weeks. Int J Gynecol Obstet. 2007, 99, S178-S181.

19. Pongsatha $\mathrm{S}$, Tongsong $\mathrm{T}$. Misoprostol for second trimester termination of pregnancies with prior low transverse cesarean section. Int J Gynaecol Obstet. 2003, 80, 61-62.

20. Rouzi A. Second-trimester pregnancy termination with misoprostol in women with previous cesarean sections. Int J Gynaecol Obstet. 2003, $80,317-318$

21. Herabutya $\mathrm{H}, \mathrm{Chanarachakul} \mathrm{B,} \mathrm{Punyavachira} \mathrm{P.} \mathrm{Induction} \mathrm{of} \mathrm{labor} \mathrm{with}$ vaginal misoprostol for second trimester termination of pregnancy in the scarred uterus. Int J Gynaecol Obstet. 2003, 83, 293-297.

22. Daponte A, Nzewenga G, Dimopoulos KD, [et al.]. The use of vaginal misoprostol for second-trimester pregnancy termination in women with previous single cesarean section. Contraception. 2006, 74, 324-327.

23. Dickinson JE. Misoprostol for second-trimester pregnancy termination in women with a prior cesarean delivery. Obstet Gynecol. 2005, 105, 352-356.

24. Herabutya $Y$, Chanarachakul $B$, Punyavachira P. Induction of labor with vaginal misoprostol for second trimester termination of pregnancy in the scarred uterus. Int J Gynaecol Obstet. 2003, 83, 293-297.

25. Dickinson JE, Evans SF. The optimization of intravaginal misoprostol dosing schedules in second-trimester pregnancy termination. Am J Obstet Gynecol. 2002, 186, 470-474.

26. Goh SE, Thong KJ. Induction of second trimester abortion (12-20 weeks) with mifepristone and misoprostol: a review of 386 consecutive cases. Contraception. 2006, 73, 516-519.

27. Jannet D, Aflak N, Abankwa A, [et al.]. Termination of 2nd 3rd trimester pregnancies with mifepristone and misoprostol. Eur J Obstet Gynecol Reprod Biol. 1996, 70, 159-163.

28. Dickinson JE, Doherty DA. Factors influencing the duration of pregnancy termination with vaginal misoprostol for fetal abnormality. Prenatal Diagnosis. 2009, 29, 520-524.

29. Ashok PW, Templeton A, Wagaarachchi PT, [et al.]. Mid-trimester medical termination of pregnancy: a review of 1002 consecutive cases. Contraception. 2004, 69, 51-58.

30. Sak ME, Soydinç HE, Evsen MS, [et al.]. Which factors may influence the duration of misoprostol-induced abortion in the second trimester? Clin Exp Obstet Gynecol. 2013, 40, 356-358. 